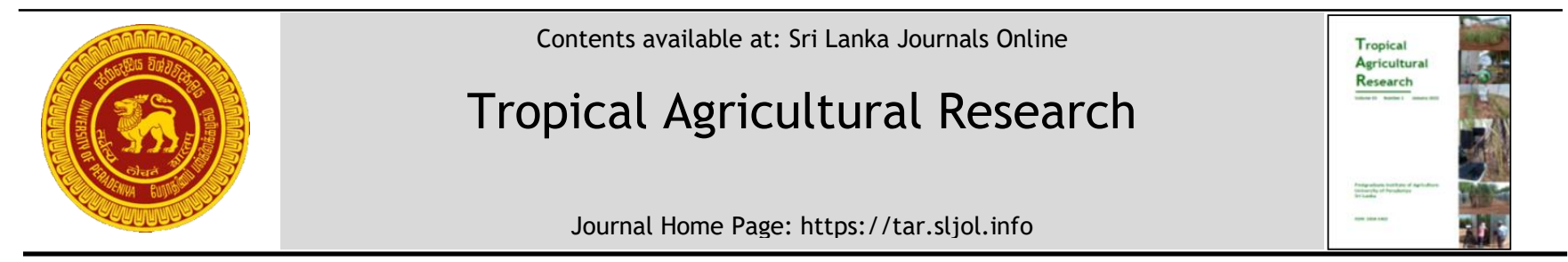

\title{
Cellulose Decomposition Potential of Soil as Affected by Vegetable Cultivation: A Case Study in Kegalle District, Sri Lanka
}

\author{
W.A.M.S. Wickramaarachchi, W.S Dandeniya* \\ ${ }^{1}$ Postgraduate Institute of Agriculture, University of Peradeniya, Peradeniya, 20400, Sri Lanka \\ ${ }^{2}$ Department of Soil Science, Faculty of Agriculture, University of Peradeniya, Peradeniya, 20400, Sri Lanka
}

\section{ARTICLE INFO}

\section{Article history:}

Received: 03 July 2021

Revised version received: 25 September 2021

Accepted: 05 October 2021

Available online: 01 January 2022

\section{Keywords:}

Cellulose decomposition

Litterbag

Organic fertilizer

Soil microorganisms

\section{Citation:}

Wickramaarachchi, W.A.M.S. and Dandeniya, W.S. (2022). Cellulose decomposition potential of soil as affected by vegetable cultivation: A case study in Kegalle District, Sri Lanka. Tropical Agricultural Research, 33(1): 01-08.

DOI: http://doi.org/10.4038/tar.v33i1.8531

Wickramaarachchi, W.A.M.S.

https://orcid.org/0000-0002-2341-5618

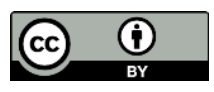

\section{ABSTRACT}

The potential of microbial communities for organic $\mathrm{C}$ decomposition is a crucial factor determining $\mathrm{CO}_{2}$ emissions from soil, C storage, and short-term nutrient turnover. We conducted a study to assess cellulose decomposition potential (CDP) of soils as affected by vegetable cultivation. Ten sites cultivated with vegetables and five sites under natural vegetation, distributed in Atulugama and Kanangama Grama Nilaldhari divisions in Kegalle District of Sri Lanka, were selected for the study. The cultivated lands have been managed with organic fertilizers $(n=4)$, synthetic fertilizers $(n=3)$, or a combination of both types of fertilizers $(n=3)$. Soils collected at 0-15 cm depth were used in a laboratory incubation experiment to assess CDP in triplicates for two weeks. The in situ CDP was studied by placing litter bags containing two types of cellulose materials, i.e. cotton wool or cellulose filter papers, separately for four and six weeks, respectively. They were placed at $5 \mathrm{~cm}$ depth in the field in two replicates. Vegetable cultivation had significantly $(p<0.05)$ reduced soil organic $C$ content. There was no significant correlation ( $p>0.05$ ) between CDP observed under laboratory and field conditions. The effect of land management on CDP was significant $(p<0.05)$ only in laboratory incubation, in which soils collected from the lands cultivated with synthetic fertilizers alone had nine-fold high CDP compared to uncultivated soils. In situ decomposition of added cellulose filter papers and cotton wool after four weeks ranged from 13-100\% and $61-65 \%$, respectively. Nearly $44 \%$ of sites exhibited values $>80 \%$ for CDP. In conclusion, vegetable cultivation affected CDP differently depending on the nature of cellulose input and the history of fertilizer management.

\footnotetext{
* Corresponding author: warshisd@pdn.ac.lk
} 


\section{INTRODUCTION}

Soil stores about 1,500 Pg of organic C, approximately twice as much $\mathrm{C}$ as in the atmosphere (Lal et al., 2003; Scharlemann et al., 2014). The carbon mineralization and decomposition (CMD) process plays a vital role in land-atmosphere $\mathrm{C}$ exchange and soil $\mathrm{C}$ storage. Further, the CMD affects the cycling of N, P, and S, contributing to short-term nutrient turnover in soil. Therefore, understanding how land management practices affect soil CMD is critical to foresee $\mathrm{CO}_{2}$ emissions and develop strategies to increase $\mathrm{C}$ sequestration for combating global warming.

Organic materials added to soil are shredded by macrofauna into smaller particles and mixed within the soil profile (Sofo et al., 2020; van Gestel et al., 2003). Through C mineralization (CM), organic $\mathrm{C}$ in materials is transformed to inorganic $\mathrm{C}$ forms, mainly $\mathrm{CO}_{2}$. However, a fraction of organic $C$ is sequestered in the soil, transforming gradually from labile substances into more stable humic substances contributing to soil organic C storage. Thus, all the organic $\mathrm{C}$ is not immediately mineralized. Therefore, the time taken for complete mineralization of an added material may depend on the number of biotic and abiotic factors (Sofo et al., 2020; Bernal et al., 1998; van Gestel et al., 2003; Hossain et al., 2017). Active-C is a major component of labile-C, and it is largely comprised of polysaccharides, proteins, nucleic acids, and carboxyl carbon freely available in the soil and microbial biomass (Rovira and Vallejo, 2002). Labile soil organic $C$ pools are considered as valuable indicators of changes in soil $C$ sequestration and dynamics induced by different soil management practices, such as application of organic amendments and synthetic fertilizers, tillage, and crop rotation (Haynes, 2000). In soil, the CMD is a complex process that involves many organisms from different strata in the food chain (van Gestel et al., 2003; Blagodatskaya et al., 2014). The efficiency of CMD in the soil is therefore predominantly determined by the functionality of microbial communities.

Previous studies suggest that the $\mathrm{CM}$ is a sensitive and reliable measure to study soil microbial activity (Bernal et al., 1998; Hossain et al., 2017). Principles of mass balancing, $\mathrm{CO}_{2}$ emissions, and tracer techniques (with ${ }^{13} \mathrm{C}$ and ${ }^{14} \mathrm{C}$ isotopes) have been used as an integrative approach to estimate the CMD (Fontaine et al., 2004; Strickland et al., 2010; Blagodatskaya et al., 2014). Decomposition of cellulolytic materials has been suggested as an effective and realistic standardized method for studying heterotrophic microbial assemblages in soil and water (Harrison et al., 1988; van Gestel et al., 2003; Colas et al., 2019). In addition, litter-bag assays are used commonly to assess organic material decomposition (Boulton and Boon, 1991; Kriauciuniene et al., 2012). Here, a known mass an organic material is placed in mesh bags in the field at the desired soil depth, and later the bags are retrieved to determine mass loss over time (Boulton and Boon, 1991).

Maintaining soil organic matter (SOM) quality and quantity is vital for safeguarding long-term soil fertility and sustainability of agricultural lands (Lal et al., 2003). While promoting the use of management practices to improve SOM, it is crucial to increase awareness among farmers on how soil biological activities support its health. Therefore, tedious, highly technical, and timeconsuming standard laboratory techniques may not be practical for the educational programs that target farmers. The objective of this study was to assess the activity of cellulolytic microorganisms in soil as affected by vegetable cultivation, employing methods compatible with visualizing data that can be used in training programs targeting farmers. Here, we determined the cellulose decomposition potential (CDP) using an in-situ litter bag study and an ex-situ soil incubation experiment. Further, we also investigated the relationship of CDP with total and active-C in soil.

\section{METHODOLOGY}

\section{Site description and soil analysis}

The study was conducted from March to April 2019 in farm fields at Atulugama (Lattitude. 6.99 $\mathrm{N}$ and Longitude. 20.26 E) and Kanangama (Lattitude. $7 \mathrm{~N}$ and Longitude. 20.27 E) Grama Nilaldhari divisions in Kegalle District, Sri Lanka. The selected region is in the Wet-zone Low country (WL) agro-climatic zone (Punyawardena et al., 2003). Ten sites cultivated with vegetables and five uncultivated sites under natural vegetation located close proximity to the cultivated sites were selected randomly for the study. Cultivated lands have been managed with organic fertilizers $(n=4)$, synthetic fertilizers $(n=3)$, or a combination of both types of fertilizers $(n=3)$. Farmers used poultry manure, cattle manure, and compost as organic fertilizers. They applied fertilizer mixtures containing urea, triple superphosphate, and murate of potash as synthetic fertilizers. All farmers applied agrochemicals to control pests and diseases. In cultivated fields, crops such as leafy vegetables, capsicum, okra, long bean, bitter guard, snake guard, eggplant, and pumpkin had been cultivated 
as mixed crops over the years at small scale (land extent $<1 / 4$ acre). Two locations were selected from each site for in-situ CDP estimation. Soil samples were collected from each sampling site at $0-15 \mathrm{~cm}$ depth in three replicates for soil analysis and laboratory incubation study (ex-situ CDP estimation). All the laboratory analyses were performed at the Department of Soil Science, University of Peradeniya, Sri Lanka.

Soil samples were air-dried and passed through a $2 \mathrm{~mm}$ sieve. The $\mathrm{pH}$ was measured in a 1:5 soil:water ratio. The organic $\mathrm{C}$ content was measured using Walkley and Black method (Nelson and Sommers, 1996) and the active-C content was measured according to the permanganate oxidizable carbon (POXC) method described by Weil et al. (2003).

\section{Soil incubation experiment}

Air-dried and sieved soil samples were moistened with water to achieve a $25 \%(\mathrm{w} / \mathrm{w})$ moisture level and incubated for three days without allowing it to dry. A quarter of cellulose filter paper (Whatmann® No.1) was placed in a sterilized petri-dish, and moist soil was packed to the petri dish and sealed well with parafilm. Three replicates were prepared for each soil sample, and the soil-filled Petri-dishes were kept under dark condition at room temperature. After two weeks, images of partially decomposed cellulose filter papers in Petri-dishes were captured using a camera. An image of a non-degraded filter paper was also captured to use as a control in image analysis. Image analysis was performed using Image-J® software. The percentage area of filter paper decomposed was estimated based on the size of the remaining piece and level of discoloration. The average decomposition percentage was calculated for filter papers incubated with uncultivated soil

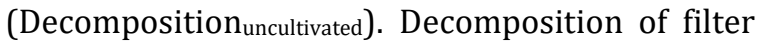
paper incubated with cultivated soil

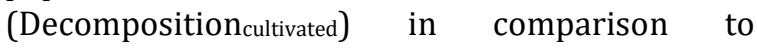

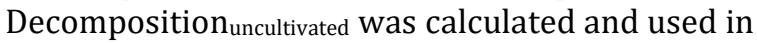
statistical analysis.

\section{In-situ test with litter bags}

In-situ testing of CDP was determined employing the litter bag technique (Fekete et al., 2008). Litter bags of $20 \mathrm{~cm} \times 7 \mathrm{~cm}$ size were prepared using Nylon shade mesh (50\% shade). Each bag was filled with $100 \mathrm{~g}$ of cotton wool (TAS MED® absorbent cotton wool for surgical purposes). The bags were buried at an angle at $10-15 \mathrm{~cm}$ depth to avoid excessive damping around litter bags. Litter bags were placed as two replicates per site.
The same procedure was repeated with placing cellulose filter papers (Whatmann $®$ No.1) weighing $1.648 \mathrm{~g}$ per litter bag. Litter bags containing cellulose filter papers and cotton wool were recovered at 4 and 6 weeks after placement in soil, respectively. The material remaining in the litter bag was recovered and carefully washed to remove soil particles with density separation. The cleaned material was oven-dried at $60{ }^{\circ} \mathrm{C}$ until a constant weight was obtained (about $24 \mathrm{~h}$ ).

\section{Statistical analysis}

Data were analyzed using the Analysis of Variance with General Linear Model (GLM) procedure to test the significance of land management using uncultivated, cultivated with organic fertilizers, cultivated with synthetic fertilizers, and cultivated with organic and synthetic fertilizers as the categories at $p=0.05$. When the effect of land management was significant $(p<0.05)$, the mean comparison was performed using the least significant difference (LSD) method at $\mathrm{P}=0.05$. Correlation between measured parameters was analyzed using Pearsons's correlation technique at $p=0.05$. Statistical analyses were performed using SAS ${ }^{\circledR}$ University edition software.

\section{RESULTS AND DISCUSSION}

Soils in the studied fields were slightly acidic and had relatively high organic $C$ content (Table 1 ). According to the recently developed soil organic $C$ map of Sri Lanka, the organic C levels in 0-30 cm depth range from 0.05 to $7.4 \%$ (Mishra \& Mapa, 2019). The same study reported that the country average for soils cultivated with annual crops is 1.5\% (Mishra \& Mapa, 2019). The high organic C content support improvement of soil structure, reduction in bulk density, and increase in soil biological properties, leading to higher soil fertility (Lal, 2003). Soils under vegetable cultivation had relatively less organic $\mathrm{C}$ content compared to uncultivated soils, but the difference was significant only in soils managed with organic fertilizers alone. Fontaine et al., (2004) observed that the addition of organic $\mathrm{C}$ accelerated the decomposition of SOM. They emphasized that competition among microorganisms for nutrient and energy sources plays an important role in organic $\mathrm{C}$ decomposition, and soil organic $\mathrm{C}$ losses increase when microbial communities are nutrient-limited. Hence, the addition of organic materials may not necessarily improve $\mathrm{C}$ storage (Fontaine et al., 2004; Blagodatskaya et al., 2014). The observed active- $C$ contents in the present study are in the range generally reported for agricultural soils (Weil et al., 2003). 
Table 1. Characteristics of soils form uncultivated lands and vegetable cultivated lands managed with three different input use systems as organic fertilizers alone, synthetic fertilizers alone and a combination of organic and synthetic fertilizers

\begin{tabular}{|c|c|c|c|}
\hline Land management category & $\mathbf{p H}$ & $\begin{array}{c}\text { Organic C } \\
\text { (\%) }\end{array}$ & $\begin{array}{l}\text { Active-C } \\
\text { (mg/kg) }\end{array}$ \\
\hline Uncultivated & $4.56 \pm 0.108{ }^{a}$ & $4.4 \pm 0.11^{a}$ & $315 \pm 31.4 \mathrm{a}$ \\
\hline \multicolumn{4}{|l|}{ Cultivated } \\
\hline Organic fertilizer & $5.11 \pm 0.359 a$ & $3.5 \pm 0.36^{b}$ & $274 \pm 35.9 \mathrm{a}$ \\
\hline Synthetic fertilizer & $5.33 \pm 0.547 \mathrm{a}$ & $3.6 \pm 0.15 \mathrm{ab}$ & $293 \pm 45.7 \mathrm{a}$ \\
\hline Organic+Synthetic fertilizers & $5.33 \pm 0.121^{a}$ & $4.1 \pm 0.10 \mathrm{ab}$ & $359 \pm 50.5^{a}$ \\
\hline$p$ value $^{1}$ & NS & $* *$ & NS \\
\hline
\end{tabular}

\section{Ex-situ analysis of cellulose decomposition potential}

In the soil incubation study, CDP was significantly affected $(P<0.0001)$ by land management. The percentage area loss in filter papers due to the decomposition ranged from 3 to $99 \%$ by the end of two weeks, with the highest variability observed in soils from lands that received both organic and synthetic fertilizers (3 to $88 \%$ ). The highest CDP was observed in lands cultivated with synthetic fertilizer inputs alone. It was nearly 9folds higher than the decomposition in uncultivated soil (Figure 1). The cultivated soils managed with organic fertilizers alone had much similar CDP to natural vegetation. An increase in C mineralization with the increase in mineral nutrient availability has been reported previously (Strickland et al., 2010). The filter paper assay was easy to perform and can be used to visualize data effectively

(Figure

2).

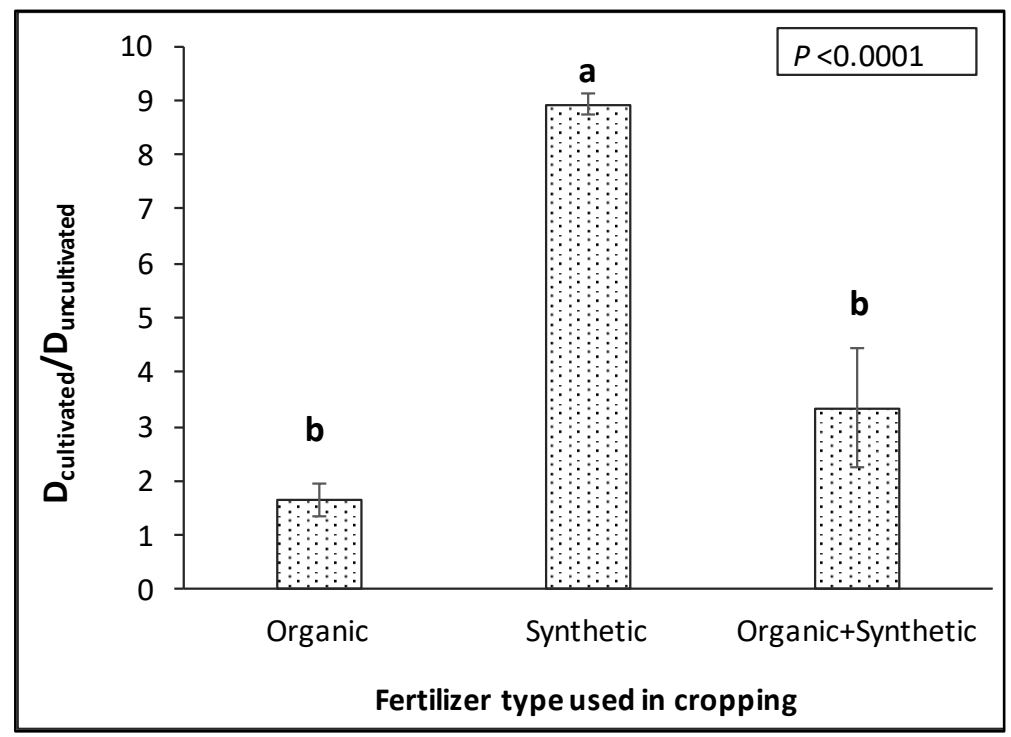

Figure 1. Decomposition status of cellulose filter papers incubated with soils collected from vegetable cultivated lands managed with organic and/or synthetic fertilizers in comparison to soil from uncultivated land (under natural vegetation) in the laboratory incubation experiment. Error bars indicate standard error. $p<0.05$ indicate that the effect of land management is significant. Means followed by the same letter are not significantly different at $\boldsymbol{p}=\mathbf{0 . 0 5}$. 


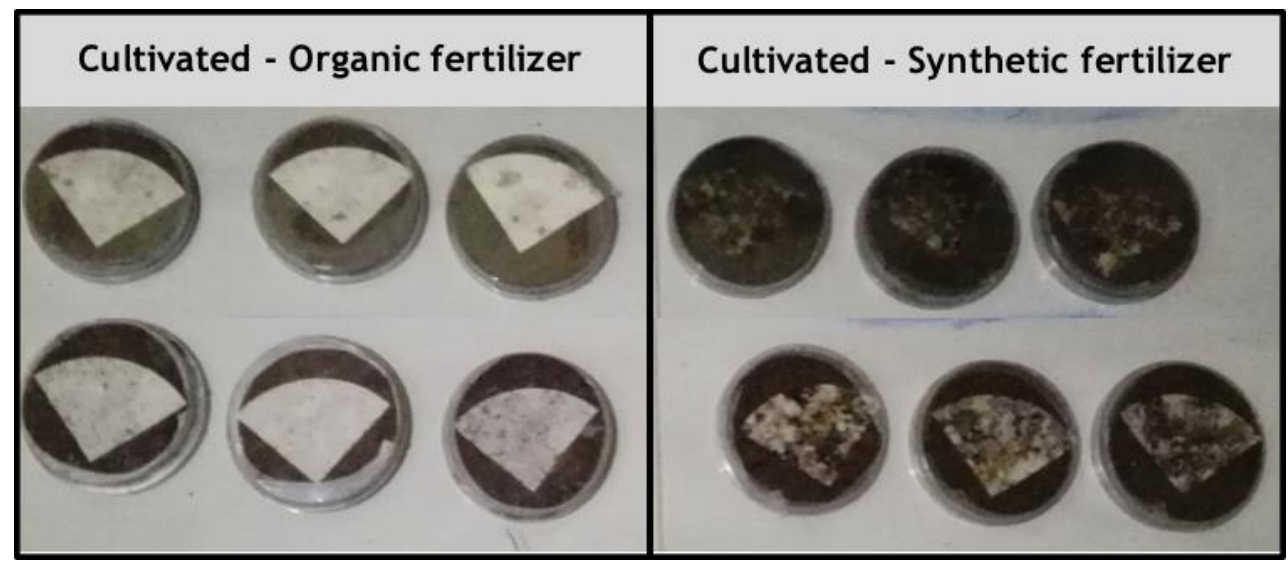

Figure 2. Status of filter paper degradation in two land management systems (cultivated with organic fertilizers alone and cultivated with synthetic fertilizers alone) at the end of two weeks of incubation.

In soil, there are r-strategist and K-strategist cellulose decomposers (Fontaine et al., 2004; Blagodatskaya et al., 2014). When a cellulose substrate is added to the soil, the fast-growing $r$ strategist cellulose decomposers would respond. They could express their full growth potential when mineral nutrients are not limiting (Fontaine et al., 2004). On the other hand, K-strategist cellulose decomposers may dominate cellulolytic microbial communities in soils that receive high organic inputs with having low mineral nutrients (Fontaine et al., 2004). Hence in soils managed with organic fertilizers alone, K-strategists get stimulated by cellulose inputs. On the other hand, r-strategist cellulose decomposers would respond to added cellulose in the soils applied with synthetic fertilizers alone. Therefore, the difference in CDP can be attributed to differences in the diversity of cellulolytic microbial communities in soil. The dominance of $r$ strategists and K-strategists in decomposers and functioning of microbial interactions affect soil organic-C content in the long run (Fontaine et al., 2004; Blagodatskaya et al., 2014). Stimulation of $\mathrm{K}$-strategist cellulose decomposers increases the decomposition of soil organic C (Fontaine et al., 2004). Therefore, soil exhibiting a high response of cellulolytic microorganisms (mainly rstrategists) to freshly added cellulose may still maintain high soil organic $\mathrm{C}$ content in the long run. Differences in CDP concerning land use/ management practices have been reported previously (Strickland et al., 2010; Asigbaase et al., 2020).

\section{In-Situ analysis of cellulose decomposition potential}

Interestingly, the effect of land management on CDP tested using cellulose filter papers and cotton wool as substrates were not significant $(p>0.05)$ under field conditions. In general, the decomposition rate of cellulose filter paper was higher than that of cotton wool and ranged from 13 to $100 \%$ and 61 to $65 \%$ over one month, respectively (Figure 3). Of the total, $44 \%$ of samples exhibited over $80 \%$ decomposition of cellulose filter papers during one month period. From these samples, 75\% were from cultivated fields. The results from ex-situ and in-situ analysis of CDP did not have a significant correlation $(P>0.05)$. It may be partly because litter bags retrieved from soil much late to observe treatment effects. In the ex-situ analysis, the samples were observed two weeks after initiating incubation. Time allowed for decomposition is an important factor influencing the results of CMD studies (Fekete et al., 2008; Dumitrache et al., 2013). Kriauciuniene et al. (2012) studied litter decomposition from 2.5 to 26 months after placement in soil, whereas Fekete et al. (2008) studied the decomposition of litter and cotton wool over 3 to 12 months after placing in the soil. Fekete et al. (2008) observed that $59 \%$ of cotton wool was degraded in 3 months in the forested ecosystem in North-Eastern Hungary. In the present study, cotton-wool degradation one month after placement in soil ranged from 61$65 \%$, indicating rapid decomposition in tropical climatic conditions. Therefore, we suggest periodical observations (e.g. weekly) within one month period on CDP when performing in-situ analysis in the future to determine the best observation window under humid tropical environments.

Mass balancing approach with litter bag studies is a comparatively easy approach to study CDP in soils though it has limitations (Boulton and Boon, 1991; van Gestel et al., 2003; Fekete et al., 2008; 
Kriauciuniene et al., 2012). One major drawback is the creation of artificial conditions such as excessive damping around the litter bag when placed in soil (Van Gestel et al., 2003). In the present study, the litter bags were placed in the soil at an angle to minimize any damping effect.

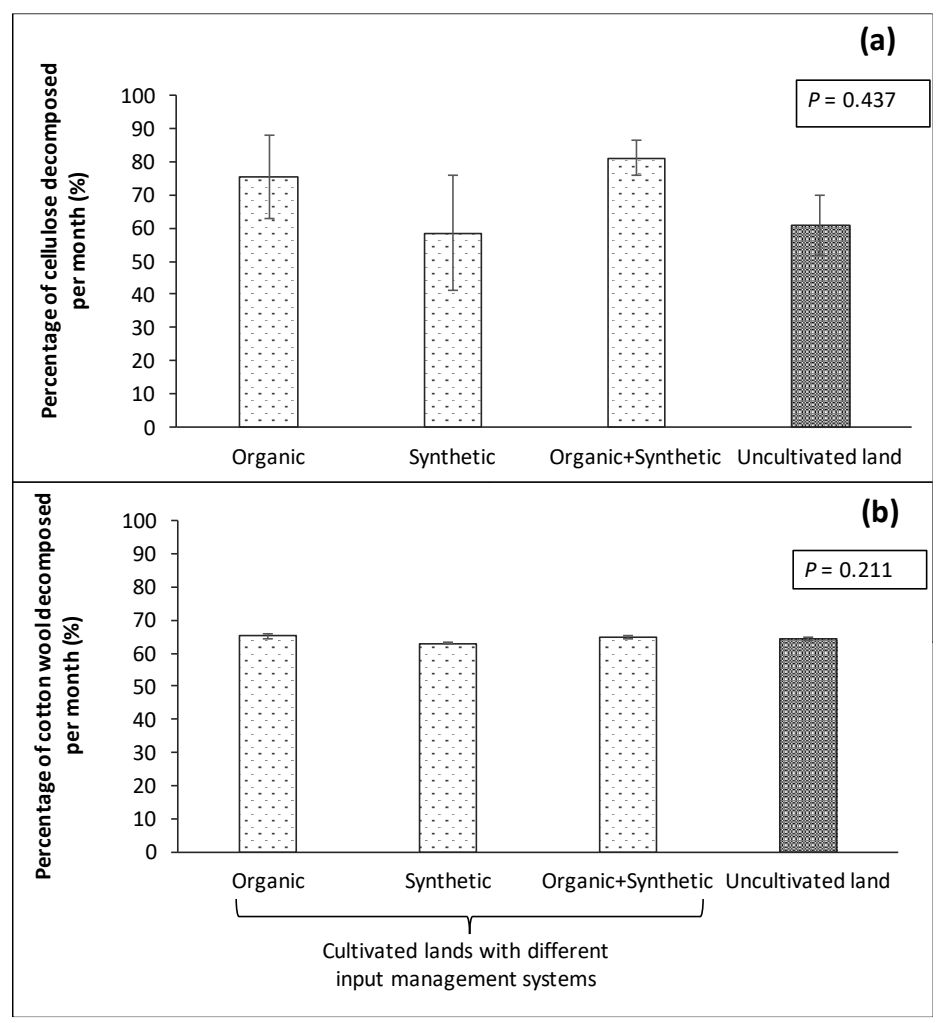

Figure 3. Decomposition rate (mass loss in grams per $100 \mathrm{~g}$ of material placed in soil for one month duration) of cellulose (a) and cotton-wool (b) in litterbags placed in vegetable cultivated and uncultivated lands at $10-15 \mathrm{~cm}$ soil depth. Error bars indicate standard error. $P>0.05$ indicate that treatment effect is not significant.

During the study period, there were frequent rainfall conditions, which is common in the Wetzone of Sri Lanka (Punyawardena et al., 2003). Soil moisture level and temperature regime are vital for cellulolytic microbial activity (Fekete et al., 2008; Hossain et al., 2017). Therefore, differences in soil moisture status and thermal conductance may also have contributed to the differences in CDP observed in-situ vs. ex-situ.

The composition of substrates affects their decomposition characteristics in soil (Fekete et al., 2008; Kriauciuniene et al., 2012). Cellulose cotton wool has been used previously in studying CMD and found to decompose faster than leaf litter owing to its homogenous structure and composition (Fekete et al., 2008). In general, surgical cotton wool used in the present study is composed of $98 \%$ cellulose in about $60 \%$ crystalline structure and fringed fibril morphology (Gupta, 2013). Whatman ${ }^{\circledR}$ cellulose filter papers contain 98\% cellulose though the fiber distribution, pores, and channels are highly heterogeneous (Dumitrache et al., 2013; Costa et al., 2014). Although both substrates used in the present study have cellulose as the main constituent, cotton cellulose differs from cellulose present in the filter paper primarily by having a higher degree of polymerization and crystallinity. The physical structure of the materials affects the accessibility for microbial penetration and subsequent colonization. The accessible surface area of cellulolytic material determines its decomposition rate (Dumitrache et al., 2013). The structural differences in cotton wool and filter paper may have contributed to observed differences in CDP. Further, cotton wool used for medical purposes has high hydrophilic characteristics with the ability to imbibe up to 30\% moisture by mass (Gupta, 2013). Therefore, the microclimate in the litter bag containing cotton wool would be different from that containing cellulose filter papers.

A significant correlation between litter decomposition and soil characters like $\mathrm{pH}$ and moisture content has been reported previously (Asigbaase et al., 2020). However, in the present 
study, CDP had no significant correlations $(p>0.05)$ with the measured soil parameters $(\mathrm{pH}$, organic $C$, and active- $C$ ). It could be because the soils were generally high in organic $\mathrm{C}$ contents and had less variability of $\mathrm{pH}$ and active-C contents (Table 1). While soil organic $C$ in the studied soils ranged from 2.3 to $4.6 \%$ the CDP assessed based on the decomposition of cellulose filter papers ranged from 3 to $98 \%$ during the two-week period in ex-situ conditions and 14 to $100 \%$ during the four-week period in in-situ. Although the $\mathrm{pH}$ and organic $\mathrm{C}$ varied in narrow ranges, it is interesting to note that CDP showed very high variability. It should be due to the difference in the diversity of microbial communities in these soils.

\section{CONCLUSIONS}

In the studied region, vegetable cultivation caused a decline in soil organic $\mathrm{C}$ content to variable degrees depending on nutrient inputs used.

\section{REFERENCES}

Asigbaase, M., Dawoe, E., Sjogersten, S., \& Lomax, B. H. (2021). Decomposition and nutrient mineralisation of leaf litter in smallholder cocoa agroforests: a comparison of organic and conventional farms in Ghana. Journal of Soils and Sediments, 21(2), 1010-1023.

Bernal, M. P., Sanchez-Monedero, M. A., Paredes, C., \& Roig, A. (1998). Carbon mineralization from organic wastes at different composting stages during their incubation with soil. Agriculture, Ecosystems \& Environment, 69(3), 175-189.

Blagodatskaya, E., Khomyakov, N., Myachina, O., Bogomolova, I., Blagodatsky, S., \& Kuzyakov, Y. (2014). Microbial interactions affect sources of priming induced by cellulose. Soil Biology and Biochemistry, 74, 39-49.

Boulton, A. J., \& Boon, P. I. (1991). A review of methodology used to measure leaf litter decomposition in lotic environments: time to turn over an old leaf?. Marine and Freshwater Research, 42(1), 1-43.

Colas, F., Woodward, G., Burdon, F. J., Guérold, F., Chauvet, E., Cornut, J., ... \& Tiegs, S. D. (2019). Towards a simple global-standard bioassay for a key ecosystem process: organic-matter decomposition using cotton strips. Ecological Indicators, 106, 105466.
Vegetable cultivation affected CDP differently depending on the nature of cellulose input and the history of fertilizer management. Carbon mineralization and decomposition efficiency, reflected by CDP were highest in vegetable cultivated soils managed with synthetic fertilizer inputs alone. Ex-situ analysis of CDP using cellulose filter papers could effectively be used to demonstrate the differences in microbial activity in soils. From the results, it is inferred that the nutrient management practices changed the diversity of the heterotrophic microbial community. It would be interesting to further investigate whether organic fertilizer usage leads to the dominance of K-strategist decomposers compared to other fertilizer management regimes under vegetable cultivation. It is suggested to periodically analyze the CDP over one month to identify the best observation point for in-situ determination of CDP in a humid tropical climate as in Kegalle, Sri Lanka.

Costa, M. N., Veigas, B., Jacob, J. M., Santos, D. S., Gomes, J., Baptista, P. V., ... \& Fortunato, E. (2014). A low cost, safe, disposable, rapid and self-sustainable paper-based platform for diagnostic testing: lab-on-paper. Nanotechnology, 25(9), 094006.

Dumitrache, A., Wolfaardt, G. M., Allen, D. G., Liss, S. N., \& Lynd, L. R. (2013). Tracking the cellulolytic activity of Clostridium thermocellum biofilms. Biotechnology for biofuels, 6(1), 1-14.

Fekete, I., Halasz, J., Kramoperger, Z., \& Krausz, E. (2008). Study of litter decomposition intensity in litter manipulative trials in Síkfőkút Cambisols. Cereal Research Communications, 36, 1779-1782.

Fontaine, S., Bardoux, G., Abbadie, L., \& Mariotti, A. (2004). Carbon input to soil may decrease soil carbon content. Ecology letters, 7(4), 314320.

Gupta, B. S. (2013). Manufacture, types and properties of biotextiles for medical applications. In Biotextiles as Medical Implants (pp. 3-47). Woodhead Publishing.

Haynes, R. J. (2000). Labile organic matter as an indicator of organic matter quality, Soil Biology and Biochemistry, 32, 211-219.

Harrison, A.F., Latter, P.M. and Walton, D.W.H. (1988). Cotton strip assay: an index of decomposition in soils 24, ITE.

Hossain, M. B., Rahman, M. M., Biswas, J. C., Miah, M. M. U., Akhter, S., Maniruzzaman, M., ... \& 
Kalra, N. (2017). Carbon mineralization and carbon dioxide emission from organic matter added soil under different temperature regimes. International Journal of Recycling of Organic Waste in Agriculture, 6(4), 311-319.

Kriaučiūnienė, Z., Velička, R., \& Raudonius, S. (2012). The influence of crop residues type on their decomposition rate in the soil: a litterbag study. Žemdirbyste Agriculture, $99(3), 227-236$.

Lal, R. (2003). Offsetting global CO2 emissions by restoration of degraded soils and intensification of world agriculture and forestry. Land Degradation \& Development, 14(3), 309-322.

Nelson, D. W., \& Sommers, L. E. (1996). Total carbon, organic carbon, and organic matter. Methods of soil analysis: Part 3 Chemical methods, 5, 961-1010.

Punyawardena, B. V. R., Bandara, T. M. J., Munasinghe, M. A. K., Banda, N. J., \& Pushpakumara, S. M. V. (2003). Agroecological regions of Sri Lanka. Natural Resource Management Centre, Department of Agriculture, Peradeniya, Sri Lanka.

Rovira, P., \& Vallejo, V. R. (2002). Labile and recalcitrant pools of carbon and nitrogen in organic matter decomposing at different depths in soil: an acid hydrolysis approach. Geoderma, 107(1-2), 109-141.

Scharlemann, J. P., Tanner, E. V., Hiederer, R., \& Kapos, V. (2014). Global soil carbon: understanding and managing the largest terrestrial carbon pool. Carbon Management, 5(1), 81-91.

Sofo, A., Mininni, A. N., \& Ricciuti, P. (2020). Comparing the effects of soil fauna on litter decomposition and organic matter turnover in sustainably and conventionally managed olive orchards. Geoderma, 372, 114393.

Strickland, M. S., Callaham Jr, M. A., Davies, C. A., Lauber, C. L., Ramirez, K., Richter Jr, D. D., ... \& Bradford, M. A. (2010). Rates of in situ carbon mineralization in relation to land-use, microbial community and edaphic characteristics. Soil Biology and Biochemistry, 42(2), 260-269.

van Gestel, C. A., Kruidenier, M., \& Berg, M. P. (2003). Suitability of wheat straw decomposition, cotton strip degradation and bait-lamina feeding tests to determine soil invertebrate activity. Biology and Fertility of Soils, 37(2), 115-123.

Mishra, U., \& Mapa, R. B. (2019). National soil organic carbon estimates can improve global estimates. Geoderma, 337, 55-64.

Weil, R. R., Islam, K. R., Stine, M. A., Gruver, J. B., \& Samson-Liebig, S. E. (2003). Estimating active carbon for soil quality assessment: A simplified method for laboratory and field use.American Journal of Alternative Agriculture, 18(1), 3-17. 